Психология. Журнал Высшей школы экономики.

2017. T. 14. № 3. C. 453-469. DOI: 10.17323/1813-8918-2017-3-453-469

\title{
Cmambu
}

\section{ПРОТИВОСТОЯНИЕ ПСИХОЛОГИЗМА И АНТИПСИХОЛОГИЗМА. ПОДВОДИТЬ ИТОГИ РАНО}

\author{
B.А. БАЖАНОВ ${ }^{\mathrm{a}}$
}

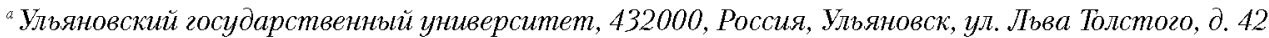

\section{Резіоме}

В статье рассматривается драматичная полемика психологизма и антипсихологизма, в результате которой благодаря бурному прогрессу классических разделов математической логики в ХХ в., казалось бы, был полностью устранен психологизм в качестве методологического основания логико-математического знания ввиду его конщептуальной несостоятельности, устаревшей и неэффективной в техническом отношении тенденции к антропологизации научных конструкций. Однако прогресс в области неклассической логики и активное развитие нейронауки, и особенно социально-культурной нейронауки, в последние годы снова выдвинули на авансцену научной и логико-математической мысли психологизм. Нами предпринимается попытка проанализировать причины перспективности психологизма в качестве одной из ведущих концепций современной когнитивной науки и показать, что онтогенетические основания социально-культурной деятельности человека и обратное влияние этой деятельности на формирование, а также динамику активности нейроструктур и их архитектонику являются важными факторами, подводящими к мысли о глубокой фундированности психологической организации, когнитивного потенщиала личности и эпистемологических сообществ активно взаимодействующими элементами целостной системы «мозг - социум - культура». Предлагается классификация подходов к интерпретации психологизма; исследуются границы деантропологизации научного знания. Показано, что психологизм оказывается онтогенетически фундированным, следовательно, установка, предполагающая возможность абсолютной деантропологизации научного знания, на которую фактически опирался антипсихологизм, в общем случае оказывается слишком категоричной. Обсуждается проявление эффекта Болдуина в эволюции живых и социальных систем, когда изменение поведения социальной системы и/или группы может вести к изменению естественных факторов отбора и, следовательно, к новым направлениям ее развития. Показано, что в соответствии с действием эффекта Болдуина

Статья написана при поддержке гранта РГНФ, проект № 16-03-00117а «Социально-культурная революция в нейронауке: предпосылки и значение для логики, эпистемологии и философии науки». 
каждая составляющая цепочки «гены - структуры - функции - опыт» находится в состоянии по меньшей мере двунаправленного взаимодействия: активность и состав генов, задающих психологический ландшафт, зависят от характера окружающей среды (в том числе культуры), а окружающая среда изменяется в результате деятельности и психологических установок возрастающей массы носителей активности данного множества генов.

Ключевые слова: психологизм, антипсихологизм, нейронаука, натурализм, онтогенетические предпосылки психологизма, эффект Болдуина.

Для человеческого мышления характерно рассуждение в формате бинарных оппозиций, дихотомий: правое - левое, интуитивное - дискурсивное, непрерывное - дискретное, четное - нечетное и т.п. (Иванов, 1978). Философская мысль пульсирует между своего рода полюсами: материализм - идеализм, историцизм - эссенциализм (Капустин, 2010), редукционизм холизм (Wheatley, 1992; Пригожин, Стенгерс, 1994), презентизм - антикваризм и т.д. (Кузнецова, 1986); в области философии языка, например, это аналитическая и постмодернистская традиция (Касавин, 2011), в области философии логики и математики - это реализм и антиреализм (Бажанов, 2014), а также психологизм и антипсихологизм. Едва ли не в каждом случае такого рода противостояния носят весьма острый и выраженный драматический характер. И это понятно, поскольку проблема выбора между антиномичными по своему характеру оппозициями часто определяет несовместимые с иными точками зрения позиции по тому или иному вопросу.

Оппозиция между психологизмом и антипсихологизмом также затрагивает многие животрепещущие философско-методологические проблемы, включая проблему стату- са самой философии как самостоятельной науки. Более того. Как справедливо замечает Г.В. Сорина, «масштабы этого спора оказываются столь велики, что он транслируется и в другие области культуры, включая лингвистику, литературоведение, политэкономию, семиотику» (Сорина, 2016, с. 281).

Как известно, естественные науки стремятся к объективно-истинному знанию, которое основывается на солидном эмпирическом фундаменте и отвечает требованиям точности, достоверности и воспроизводимости. Психологическое знание в этом смысле сильно уступает естественнонаучному: оно, вообще говоря, не может претендовать ни на соответствующую точность и достоверность, ни даже на должную степень воспроизводимости (Belluz, 2015; Вачков, Вачкова, 2016). Это знание по своей природе глубоко субъективно. Психология тяготеет к дескриптивности, тогда как логика и математика к безусловной прескриптивности, а логике приписывается нормативный статус (Benthem, 2008, p. 82; Stenning, Lambalgen, 2008, p. VI). Может ли психология в таком случае претендовать на то, чтобы быть надежным фундаментом и/или хотя бы некоторым фактором объяснения логико-математической реальности, 
которая par excellence удовлетворяет требованиям строгости и аподиктичности? Могут ли психологические соображения открывать путь к пониманию истоков и природы этой реальности? Если логика - это наука о приемлемых способах рассуждений, а стало быть, так или иначе касается феномена мышления, то вправе ли мы все-таки вынести за скобки, проигнорировать ту область знания, которая непосредственно занимается анализом мыслительных процедур, - психологию, которая собственно и подразумевает такое методологическое направление в философии логики и математики, как психологизм? Полагаю, что ответ на последний вопрос должен быть отрицательным. Психологизм как методологическое направление в философии логики и математики не просто допустим, а неизбежен и очень перспективен. «При анализе природы рассуждений психология без логики неэффективна, а логика без психологии просто слепа», - справедливо замечает М. Урбанский (Urbanski, 2011, p. 183).

Здесь уже уместно уточнить, что понимается под психологизмом и антипсихологизмом. Это методологические подходы, один из которых по отношению к логике и математике рассматривает их как науки, признающие существование особых «законов мышления» или, по меньшей мере, соответствуюшей онтогенетической реальности и воплощающие эти «законы» в некоторой объективированной форме - в виде рассуждений, представленных в языковом материале (психологизм), а другой отрицает саму возможность истолкования логики и математики как своего рода моделей мышления, связывая их законы лишь с материей рассуждения, не признавая их имманентную укорененность в живом процессе мышления (антипсихологизм).

Впрочем, разброс интерпретаций феномена психологизма достаточно велик - от сведе́ния данных эмпирических наук к комплексу чувственных восприятий (К. Поппер) до установки, состоящей в анализе социальных явлений исключительно в психологических терминах (Д. Блур).

По отношению к социологии психологизм предлагает объяснение социальных явлений посредством апелляции к свойствам личности и/или определенного национального характера, когда, например, причины войн и конфликтов усматриваются в естественным образом присущей отдельной человеческой личности агрессивности (Фромм, 2007). Более того, социологизм зачастую рассмат ривается как развитие линии психологизма (Kusch, 1995, p. 14-15).

Если несколько упростить ситуацию, то речь здесь идет о принципиальной сводимости или несводимости логико-математических структур к психологическим или нейропсихологическим основаниям, а также о признании или непризнании факта доминирования в познавательном процессе в большей или меньшей степени элементов психологической или нейропсихологической организации индивида. Можно даже сказать сильнее: психологизм предполагает решающую роль субъекта и его активности в науке и культуре, процесс своего рода субъективизации и натурализации познания, осознание того, что знание - это результат деятельности «живого» субъекта 
(Сорина, 2012, с. 28-29). Полагаю, что вообще феномен активности субъекта в процессе познания вряд ли можно реконструировать и понять вне и помимо некоторых представлений, свойственных именно психологизму.

\section{Истоки противостояния}

Начало противостояния психологизма и антипсихологизма восходит примерно к 1870 г,, когда гегельянец И. Эрдман в этих терминах попытался охарактеризовать философские взгляды Э. Бенеке. С тех пор на баррикадах психологизма сражались такие мыслители, как Р. Авенариус, А. Бэн, В. Вундт, У. Джемс, Хр. Зигварт, Т. Липпс, Э. Мах, Дж. Милль, Ж. Пиаже, Г. Спенсер, Б. Эрдманн, а антипсихологизм еще до своего явного оформления был представлен Лейбницем, Б. Больцано, затем Ф.Г. Брэдли, Л. Витгенштейном, Э. Гуссерлем, Р. Карнапом, Ч. Пирсом, Г. Фреге. Колебались между позициями психологизма и антипсихологизма И. Кант, И.Ф. Гербарт, Г. Лотце, П. Наторп. Аргументация обеих сторон на различных этапах споров подробно представлена в работах М. Куша (Kusch, 1995, 2015). Ирония судьбы заключается в том, что обвинений в психологизме не избежали даже сами родоначальники антипсихологизма - Г. Фреге (со стороны видного философа математики Ф. Китчера), Ч. Пирс (со стороны Дж. Кассера) и Э. Гуссерль (со стороны известных представителей аналитической философии У. Сел- ларса и М. Даммета). Аналитическая философия провозгласила «восстание против Фреге», имея в виду критическое осмысление его аргументов против психологизма, которые были сочтены как недостаточно убедительные (Kusch, 1995, p. 5, 7).

В России к сторонникам психологизма можно отнести Н.Я. Грота, М.И. Владиславлева, В.А. Снегирева, В.Н. Ивановского, М.М. Троицкого, Г.И. Челпанова, И.И. Ягодинского, а по некоторым позициям и А.И. Введенского, который хотя и возражал против сведения логики к психологии, но все-таки рассматривал логику в качестве части теории познания (Бажанов, 2007; Попова, 2015). В.Н. Ивановский анализировал ассоцианизм, а в своих воззрениях на природу логики также склонялся к психологизму (Ждан, 2012).

Н.Я. Грот считал, что логика как бы вытекает из психологии, поскольку любой анализ познавательной деятельности предполагает применение психологических методов. М.И. Владиславлев определял логику как науку о приемах мышления и душевной деятельности, соединяющую мысли в «одно целое». Г.И. Челпанов был убежден, что психология должна являться основой философских наук, куда включалась и логика (Попова, 2015, с. 574-575).

Н.А. Васильева ${ }^{1} \quad(1880-1940)$ также можно отнести к сторонникам более или менее сильной версии психологизма на том основании, что операция отрицания в его «воображаемой логике» определяется в некотором «воображаемом мире»

${ }^{1}$ Н.А. Васильев стоял у истоков научной судьбы А.Р. Лурии (Бажанов, 2008). 
соответствующей психологической организации познающего субъекта. Он обосновывал допустимость неаристотелевой логики устройством психики и восприятия, смыслом и природой отрицания в воображаемых мирах, которые по своей онтологии отличаются от нашего, земного мира и в которых могут сушествовать не только положительные, но и отрицательные ощущения (Бажанов, 2009). Н.А. Васильев осмысливал природу эмпирических элементов аристотелевой логики, элементов, непосредственно обусловленных организацией и устройством нашего мира и органов чувств человека. Наш мир устроен так, что в нем имеются несовместимые свойства, а в мышлении - соответствующие им несовместимые предикаты, сравнение которых лежит в основе отрицания, размышлял ученый. Отрицательные суждения получаются как выводы из положений о несовместимости двух признаков предмета. Человеческое устройство не допускает отрицательных ощущений, например, небелого цвета. Можно получить только положительные ощущения красного, зеленого и других цветов. Утверждая, что предмет небелого цвета, человек фактически делает заключение, что предмет красного, зеленого и т.д. цвета, а красное, зеленое и т.д. не может быть белым. Психологический процесс восприятия протекает здесь сокращенно, свернуто, «настолько быстро и механично, что не доходит до сознания» (Васильев, 1912, c. 214).

Впрочем, еще в начале XIX в. А.С. Лубкин видел в логике «антропологическую» науку, которая демонстрирует способы управления разумными способностями и позволяет здраво судить о вещах (Лубкин, 1807). Традиционный подход к логике, которым пользовался А.С. Лубкин, был «пропитан» антропологическими по своему существу установками, которые и выразились в концепции психологизма, призывавшей заниматься изучением «реального» мышления, а не нормативностью логических законов и соответствующих принудительных мыслительных конструкций. Математическое же направление в логике (нетрадиционное в смысле своей новизны и отношения к логике Аристотеля), которое постоянно укреплялось с середины XIX в., делало акцент как раз на нормативность и принудительность логических конструкций, занимая тем самым последовательно антипсихологические позиции.

Именно идеология антипсихологизма явилась мощным катализатором развития математической логики в XIX и особенно в XX в. (Pechhaus, 1999). Вообще психологизм в данный период истории активно преодолевался в направлениях, связанных с установками последовательного платонизма и/или (реже) социологизма.

Линия психологизма с торжеством математической логики не исчезла, но затаилась. Фактически она продолжилась в более интеллектуально гибких и тонких концепциях типа интуиционизма (Л.Э.Я. Брауэр, A. Гейтинг) или эффективизма (Э. Борель, А. Лебег, А. Пуанкаре, Н.Н. Лузин), О том, что потенциал психологизма был востребован и в эпоху гордого и, казалось бы, безусловного торжества математической логики, свидетельствуют идеи 
Дж. фон Неймана о логике и математике как «вторичном» языке, надстроенном над «первичным» языком мозга, а также биологической (нейрофизиологической) предзаданности логики и математики (Тростников, 1975). Фон Нейман высоко ценил теорию формальных сетей У. Маккаллока и У. Питтса, в которой логика связывалась с нейронными сетями и демонстрировалось, что однозначное грамматическое (синтаксическое) описание можно выразить посредством конечной нервной сети, что эти сети могут выполнять любые преобразования, которые реализуются на дискретных устройствах с конечной памятью. Продолжая эту аналогию, которая фиксирует факт работы мозга как целостной системы в условиях отказа (травмы) ряда его областей, фон Нейман выдвинул революционную идею построения надежной (т.е. действующей без сбоев) вычислительной машины на основе элементной базы из ненадежных компонентов. До фон Неймана считалось, что функции каждого элемента потенциальной вычислительной системы жестко детерминированы: выход из строя какого-либо элемента означает прекращение работы всей системы и поэтому все элементы должны быть надежными. Любой компьютер (цифровой или аналоговый), по мнению фон Неймана, представляет собой систему, которая оперирует дигитальными, а не символьными данными в процедурах, задаваемых определенной логикой. Таким образом, мозг некоторым образом совершает громадное число сложных вычислений. Число элементов мозга существенно превышает число эле- ментов компьютера, хотя для искусственных систем работа в параллельном режиме может быть трудно реализуемой. При этом «логический подход и структура естественного автомата ожидаемо значительно отличается от искусственного автомата... Нервная система передает численные данные посредством периодических или близкими к таковым, сериями импульсов... это позволяет ей делать надежно сложнейшую работу на довольно низком уровне точности операций первичных элементов» (Neumann, 2000, p. 52, 77).

Ключевой концептуальной проблемой для А. Тьюринга являлся вопрос: каким образом человеческий интеллект может стать продуктом различных операций нейронных сетей, которые являются в некоторым смысле «рутинными» и никоим образом не выражают природу «сознания» (mindless)?

Нейронные сети, по мысли Тьюринга, функционируют согласно алгоритмам, которые являются «вычисляемыми» и, следовательно, могут быть реализуемыми с помощью (универсальных, а также с «оракулом») «машин Тьюринга», т.е. на вычислительных устройствах технической природы. Идеи Тьюринга о воспроизведении нейронными сетями ментальных функций максимально полно реализовали Маккаллок и Питтс. Фактически именно они открыли конкретные способы использования логико-математических представлений о вычислимости в нейронных сетях посредством «машин Тьюринга» (Copeland, 2013). В области современных разработок искусственного интеллекта применяются немонотонные логики, кото- 
рые неявно предполагают психологизм (Pelletier, Elio, 2005).

Кроме того, оказался возможен своеобразный синтез психологических и антипсихологических установок (Маслов, 1986; Брюшинкин, 1988).

Бурный прогресс в области неклассических логик, комплекса когнитивных наук и особенно культурной нейронауки (Бажанов, 2015) вновь вывел на авансцену концепцию психологизма. Еще в середине 1970-х гг. известная исследовательница девиантных (неклассических) логик С. Хаак писала, что «хотя одно время было довольно обычно утверждать, что принципы логики тождественны “законам мышления”... энергичная критика этой точки зрения Г. Фреге была настолько влиятельной, что психологизм фактически лишился какойлибо поддержки. Тем не менее в настоящий момент аргументы Г. Фреге против психологизма представляются не столь убедительными и концепция психологизма значительно более правдоподобна, чем это принято ныне считать» (Haack, 1978, p. 238). Авторитет Г. Фреге был на протяжении значительного периода в XX столетии настолько велик и непререкаем, что психологизм был не просто вытеснен на периферию логико-математической мысли, а о нем даже было как-то неприлично рассуждать.

\section{Реванш психологизма}

Сейчас уже нет никаких сомнений, что «психологизм возвращается!», причем этому способствует анализ природы математики (Heinz,
2005, p. 42), равно как и логических оснований познавательной деятельности (Macnamara, Reyes, 1994). Ведущие мировые логики твердо заявляют, что «в то время как (классическая. - B.E.) математическая логика должна избегать психологизм, новейшие логические исследования не могут без него обойтись.. При анализе рассуждений психологизм без логики не убедителен, тогда как (современная. - B.E.) логика без психологизма слепа» (Gabbay, Woods, 2001, p. 141). Возражения со стороны антипсихологизма подвергаются усиленной ревизии, и можно даже утверждать, что в определенном смысле обесцениваются, в частности, аргументы, связанные с нормативным характером логико-математического знания (Aach, 1990; Grzegorczyk, 1998; Jacquette, 1997, 2003).

Настоящий ренессанс психологизма обусловлен мошным прогрессом нейронаучных исследований, которые ныне принято оценивать как революцию в понимании когнитивных процессов, поскольку эти исследования не просто идут дальше, а кардинально пересматривают стандарты и установки традиционной нейронауки (Boone, Piccinini, 2016, p. 1509). Неофиты современной нейронауки даже уверяют, что она реально поможет нашему обществу «стать лучше» (Iacoboni, 2007) или, по крайней мере, преобразовать консервативную систему образования, поскольку позволит людям сохранять их личностную идентичность (De Vos, 2016, p. 143). Здесь мы наблюдаем своего рода реминисценцию феномена антропологизма, который был присущ отечественной 
логике и гносеологии до октябрьского переворота 1917 г., причем, думается, неслучайно этот феномен связывается с новейшими логическими исследованиями. Так, немонотонные рассуждения, по мнению некоторых логиков, могут быть объяснены и обоснованы только с позиций последовательного психологизма (Pelletier et al., 2008, p. 11, 35, 50; Pelletier, Elio, 2005).

В новой интерпретации линия психологизма выражает эмпирический и натуралистический подход к эпистемологии и метафизике, поскольку предмет изучения (в логике и/или математике) тем или иным образом связан или коррелируется с психологической или нейропсихологической реальностью. В случае «слабой» версии психологизма логико-математические принципы в той или иной мере завязаны на разум или в конечном счете могут быть сформулированы при помоши психологических представлений; в «сильной» версии логика (равно как и многие разделы математики) рассматривается в качестве ветви психологии.

«Сильная» версия психологизма однозначно предполагает принятие сильной версии релятивизма. Между тем «слабая» версия позволяет избежать очевидных недостатков последнего и пройти между Сциллой дескриптивизма в истолковании ментальных явлений и Харибдой антипсихологизма, начисто отрицающего какие-либо связи логических процедур и психологических процессов. По существу, антипсихологизм представляет вариант антинатурализма (Hanna, 2006, p. 9-10). Если натурализм (как онтологиче- ский, так и эпистемический) предполагает опору в виде эмпирического научного знания и предполагает своего рода номологическое единство структурных уровней реальности, то антинатурализм обычно отказывает им в такого рода качестве. Феноменологический антинатурализм (например, в лице Э. Гуссерля) в определенном смысле продолжает кантовскую линию трансцендентализма, когда субъект познания рассматривается как обладающий универсальными когнитивными характеристиками, понимается внеситуативно и тем самым не допускает какую-либо связь субъекта познания с эмпирическими (психологическими и уж тем более нейропсихологическими) основаниями (Pearson, Protive, 2016, p. 36).

Если подытожить размышления С. Хаак (Haack, 1978) и П. Тагарда (Thagard, 1993, р. 7), то можно представить эту ситуацию с «логикой» ментальных процессов наглядно, в виде таблицы (см. таблицу 1).

Различные подходы к интерпретации психологизма дифференцируются на:

1) «психологический индивидуализм», который, по существу, и является психологизмом в традиционном понимании классической науки;

2) «психологический дескриптивизм», который характеризует познавательные стратегию и тактику больших групп людей, вовлеченных в когнитивную деятельность;

$3)$ «когнитивный конструктивизм», который рассматривает, как и в какой степени совпадают познавательные процедуры, используемые людьми, и их логико-математический 
Таблица 1

Сравнение подходов к психологизму

\begin{tabular}{|l|c|c|c|}
\hline $\begin{array}{c}\text { Версии психологизма/ } \\
\text { Философские направления }\end{array}$ & Дескриптивизм & Прескриптивизм & $\begin{array}{c}\text { Угроза } \\
\text { релятивизма }\end{array}$ \\
\hline Слабая версия психологизма & $\begin{array}{c}\text { незначительно } \\
\text { выражен }\end{array}$ & $\begin{array}{c}\text { незначительно } \\
\text { выражен }\end{array}$ & нет \\
\hline Сильная версия психологизма & да & да & да \\
\hline Антипсихологизм & нет & нет & нет \\
\hline
\end{tabular}

инструментарий, применяемый в этих процедурах;

4) «идеальный субъект познания» (The Ideal Cognizer), который фактически смыкается с идеей трансцендентального субъекта, обладающего безграничным и универсальным познавательным потенциалом, позволяющим ему получать абсолютно истинное знание (Pelletier et al, 2008, p. 7-9), а также

5) «интенциональный психологизм», который позволяет интерпретировать сознание с феноменологической точки зрения (Pitt, 2009);

6) «логический психологизм», который усматривает правильность дискурса в его соответствии принятым языковым практикам и апробированным схемам рассуждений (Lehan-Streisel, 2012, p. 576);

7) Р. Ханна предложил еще один вариант психологизма, который он назвал «логическим когнитивизмом». Смысл последнего он усматривает в том, что логические структуры в виде своего рода протологики (в смысле близком к универсальной грамматике Н. Хомского ${ }^{2}$ ) даже предопределяют психологическую организацию, а не наоборот (Hanna, 2006) ${ }^{3}$.

О протологике можно также говорить, имея в виду идею последовательного рассуждения, фундированную уже уровнем оперирования знаками (Шалак, 2014).

\section{Психологизм и пределы деантропологизации научного знания}

Прогресс современной нейронауки свидетельствует в пользу реального существования нейродинамических архетипов, образовавшихся в процессе длительной эволюции живых организмов, причем механизмы действия этих систем являются универсальными для любых живых организмов, в достаточной мере продвинутых по эволюционной лестнице (Cantlon, 2012). Речь идет о наличии некоторых базисных систем (core systems), представляющих

\footnotetext{
${ }^{2}$ Дискуссии о существовании/несуществовании универсальной грамматики Н. Хомского ведутся уже достаточно давно. Недавно обнаружены новые аргументы, которые свидетельствуют в пользу правомерности концепции универсальной грамматики (Futrell et al., 2015).

${ }^{3}$ Возражения против концепции Р. Ханна представлены, например, Дж. Коллинзом (Collins, 2009).
} 
собой врожденные структуры мозга и состоящие из автономных модулей, которые обеспечивают наиболее важные с точки зрения гомеостазиса функции живого (Kinzler, Spelke, 2007). Эти системы включают инструменты, которые призваны фиксировать объекты, попадающие в поле зрения организма; руководят его конкретными действиями; симультанно осознают количество объектов (понятия «number sense» или «numerosity»); обеспечивают ориентацию в пространстве; осуществляют коммуникацию с ближайшими партнерами и позволяют «нас» противопоставлять «им», т.е. реализуют механизм «свой чужой».

Сколь угодно сложные виды материальной и духовной деятельности строятся на фундаменте этих достаточно простых по своим функциям модулей. В пределах каждого нейронного когнитивного модуля действуют некоторые естественные «ограничители». Эти модули (и, соответственно, ограничители) обеспечивают и те познавательные механизмы, которые не представлены специальными модулями. Так, для естественного языка пока не найдено особого модуля. Овладение естественным языком и его и использование зависит от работы других модулей и таких ограничителей, как сенсомоторные факторы, когнитивные пределы обучения и личностного развития (скажем, допустимый объем памяти), особенности категоризации и упорядочения поступающей информации (Chater, Christiansen, 2010, p. 1135-1136).

Навигационные системы (модули) мозга работают на составление нейрокогнитивных карт окружающей обстановки, в которых распознается положение организма в пространстве. Данные карты имеют выраженный динамический характер, поскольку группы нейронов возбуждаются лишь тогда, когда организм оказывается в определенных участках своего ареала, и пока он там находится, они остаются возбужденными. Функционирование мозга в зависимости от культурных традиций порождает две системы пространственной ориентации - эгоцентрическую и геоцентрическую (Rizzolatti, Craighero, 2009). В эгоцентрической системе сам индивид предстает в качестве начала системы координат и описывает предметы в зависимости от их нахождения по отношению к нему. В геоцентрической системе, которая свойственна некоторым племенам австралийских аборигенов и отчасти связана с особенностями их естественных языков, отсчет ведется по сторонам света (на «запад», «восток» и т.п. от человека), причем такого рода нейрокартирование наблюдается с раннего детства и присуще даже слепым от рождения людям (Levinson, 2003).

Качество симультанно осознавать небольшое количество объектов (не более трех-четырех элементов), сравнивать их с точки зрения объема также сформировалось в процессе длительной эволюции (субитация) (Dehaene, 2011). Даже только что родившиеся младенцы без какоголибо языкового опыта уже способны различать малые количества. Субитация как нейропсихологический феномен подчиняется психофизическому закону Вебера-Фехнера, который связывает логарифмической 
зависимостью интенсивность ощущения и раздражителя ${ }^{4}$ и лишь в весьма ограниченных пределах совершенствуется по мере взросления.

Все когнитивные модули предзаданы нейрофизиологической архитектурой мозга и тем самым выражаются через те или иные психологические установки и формы познавательной активности субъекта. Психологизм, таким образом, оказывается онтогенетически фундированным, следовательно, утверждение об абсолютной деантропологизации научного знания в общем случае оказывается слишком сильным.

Если иметь в виду процедуры поиска (логического) вывода и собственного вывода, то, как показал В.Н. Брюшинкин, в процедурах поиска вывода, которые фактически ведутся на метатеоретическом уровне, не могут обойтись без психологических компонентов, «человеческого фактора». В самом же выводе, который носит принудительный характер в силу следования определенным логическим законам, психологические моменты выведены за скобки (Брюшинкин, 1988).

\section{Феномен психологизма в контексте коллективного субъекта познания}

Население планеты Земля не является гомогенным в смысле содержания и географического распределения генофонда. В культурах, которые принято относить к коллек- тивистским (к ним обычно относят восточные культуры), преобладают индивиды с короткими аллелями определенного типа (5-HTTLPR). Эти культуры порождают холистический (чаще говорят - диалектический) дискурс. В культурах, которые принято относить к индивидуалистическому типу (к ним принадлежат западные культуры), преобладают особи с иным генофондом (Chiao et al., 2010, р. 359). У них доминирует аналитический дискурс. C точки зрения характера межкультурной коммуникации это так называемые высоко- и низкоконтекстуальные культуры, которые различаются по механизмам восприятия, особенностям понимания и манерам общения (Hall, 1966). Если рассуждение трактуется как акт коммуникации, система трансляции идей из одной культурной или научной области в другую, то этот феномен можно также описывать в терминах логикокультурных доминант (Сорина, 1993).

Эпигенетический ландшафт формируется посредством действия «ограничителей», определяющих каналы и динамику развития генофондов. Здесь действует эффект Болдуина: изменение поведения социальной системы и/или группы может вести к изменению естественных факторов отбора и, следовательно, к новым направлениям ее развития. Таким образом, каждая составляюшая цепочки «гены - структуры - функции опыт» находится в состоянии, по меньшей мере, двунаправленного

\footnotetext{
${ }^{4}$ Увеличение интенсивности ощущения в арифметической прогрессии возможно при росте интенсивности раздражителя в геометрической прогрессии.
} 
взаимодействия: активность и состав генов зависят от характера окружающей среды (в частности, культуры), а окружающая среда постепенно изменяется в результате деятельности возрастающей массы носителей активности данного множества генов. Биологические факторы жизнедеятельности организма не просто тесно переплетены с социальнокультурными факторами его существования, но и оказываются взаимозависимыми в значительной степени. С нейропсихологической точки зрения здесь имеется в виду работа генетических механизмов приобретения социально-культурного опыта путем задания общих принципов построения и настройки нейронных контуров мозга, а в социально-культурном аспекте - о не замечаемой ранее глубинной фундированности соответствующей психологической организации и характера когнитивной деятельности физиологической организацией человеческого организма и, главное, его мозга. Происходит многоступенчатый процесс трансформации эпигенетических особенностей в социальные (и обратно).

Многообразие эпигенетического ландшафта, которое предопределяет когнитивные особенности различных групп населения - носителей разных генофондов, позволяет изучать проявление этих особенностей на уровне того, что принято называть «коллективным» субъектом познания. Возможно, что в некотором смысле можно говорить о намечающихся контурах социальной нейроэпистемологии.

\section{Литература}

Бажанов, В. А. (2007). История логики в России и СССР. Копщептуальный контекст университетской философии. М.: Канон ${ }^{+}$.

Бажанов, В. А. (2008). Первый учитель А.Р. Лурии: Н.А. Васильев как психолог. Методология и история психологии, 2, 69-78.

Бажанов, В. А. (2009). Н.А. Васильев и его воображаемая логика. Воскрещение одной забытой идеи. М.: Канон ${ }^{+}$.

Бажанов, В. А. (2014). Разновидности и противостояние реализма и антиреализма в философии математики. Возможна ли третья линия? Вопросы философии, 5, 52-64.

Бажанов, В. А. (2015). Современная культурная нейронаука и природа субъекта познания: логико-эпистемологические измерения. Эпистемология и философия науки, 3, 133-149.

Брюшинкин, В. Н. (1988). Логика, мыиление, информация. Л.: Изд-во Ленинградского университета.

Васильев, Н. А. (1912). Воображаемая (неаристотелева) логика. Журнал Министерства народного просвещения. Новая серия, август, 207-246.

Вачков, И. В., Вачкова, С. Н. (2016). Воспроизводимость психологических экспериментов как проблема постнеклассической науки. Культурно-историеская психология, 12(1), 97-100.

Ждан, А. Н. (2012). В.Н. Ивановский как мыслитель. В кн. В. А. Бажанов (ред.), Логико-гносеологическое направлетие в отечествениой философии (первая половина ХХ века): М.И. Каринский, В.Н. Ивановский, Н.А. Васильев (с. 127-182). М.: РОССПЭН.

Иванов, В. В. (1978). Чет и нечет. Асимметрия мозга и знаковых систем. М.: Сов. радио.

Капустин, Б. Г. (2010). Критика политической философии. Избранные эссе. М.: Территория будущего. 
Касавин, И. Т. (2011). Познание и язык. Эпистемология и философия науки, 4, 5-15.

Кузнецова, Н. И. (1986). История науки как гуманитарная дисциплина. В кн. Проблемы гуманитарного познатия (с. 141-168). Новосибирск: Наука.

Лубкин, А. С. (1807). Начертание логики. СПб.

Маслов, С. Ю. (1986). Теория дедуктивных систем и ее применения. М.: Радио и связь.

Попова, В. С. (2015). Психологизм как логико-методологическая проблема: исторические корни в русской философии начала XX века и современное значение. Психология и психотехника, 6, 570-577. doi:10.7256/2070-8955.2015.6.15508

Пригожин, И., Стенгерс, И. (1994). Время, хаос, квант. М.: Прогресс.

Сорина Г. В. (1993). Логико-культурная доминалта. Очерки теории и истории психологизма и антипсихологизма в культуре. М.: Прометей.

Сорина, Г. В. (2012). Проект «психологизм-антипсихологизм» в метатеоретическом контексте. Ращио. и, 8, 20-45.

Сорина, Г. В. (2016). Диалог методологических концепщий. Сибирский философский журнал, $14(1), 280-297$.

Тростников, В. Н. (1975). Конструктивные процессы в математике. М.: Наука.

Фромм, Э. (2007). Анатомия человеческой деструктивности. М.: АСТ.

Шалак, В. И. (2014). Протологика и ее структура. Лоимеские исследования, 20, 198-212.

Ссылки на зарубежные источники см. в разделе References после англоязыиного блока.

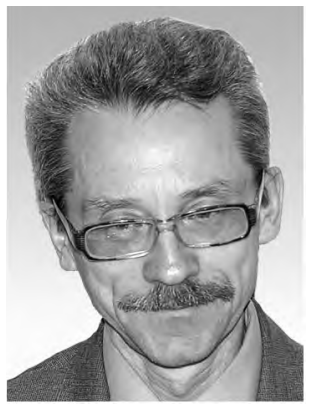

Бажанов Валентин Александрович - заведующий кафедрой философии, Ульяновский государственный университет, заслуженный деятель науки РФ, доктор философских наук, профессор.

Сфера научных интересов: история и философия науки, эпистемология, культурная нейронаука, история русской философии и логики. E-mail: vbazhanov@yandex.ru

\title{
Opposition of Psychologism and Antipsychologism. Too Early to Sum Up the Outcome
}

\author{
V.A. Bazhanov \\ Ulyanozsk State University, 42 L. Tolstoy Str., Ulyanozsk, 432000, Russian Federation
}

\begin{abstract}
The article deals with the dramatic opposition of psychologism and antipsychologism. Due to the evident success of classical branches of mathematical logic in the XX century psychologism was completely eliminated as a methodological basis for logical and mathematical knowledge for its conceptual insolvency, as an outdated and technically inefficient trend towards
\end{abstract}


anthropologization of scientific theories. However, non-classical logic's and recent neuroscience's (especially socio-cultural neuroscience) vigorous development has again brought psychologism to the proscenium of science and logico-mathematical thought. We are making attempt to analyze the reasons for the revival of psychologism and vistas to preserve its position as one of the modern cognitive science leading conceptions. We ponder over the ontogenetic foundations of the socio-cultural activity of man and the reverse effect of this activity on the formation, as well as the dynamics of activity of neural structures and their architectonics. They are the important factors related to the deep foundations of the psychological organization and cognitive potential of personality, as well as of epistemological communities due to active interaction of elements within the integral system "brain-society-culture". A classification of approaches to the interpretation of psychologism is proposed; the boundaries of the deanthropologization of scientific knowledge are under scrutiny. We show that psychologism has solid ontogenetic background and, consequently, an absolute deanthropologization of scientific knowledge, actually presupposed by antipsychologism, in the general case turns out to be too categorical and unattainable. The manifestation of the Baldwin effect in the evolution of living and social systems is discussed, when a change in the behavior of a social system and/or group can lead to a change in the natural selection factors and, consequently, to new directions of its development. We judge that in accordance with the Baldwin effect, each component of the chain "genes - structures functions - experience" is in a state of at least bi-directional interaction: the activity and composition of the genes that set the psychological landscape depend on the nature of the environment (culture included). The environment changes as result of the activity and psychological attitudes of the increasing mass of carriers of the activity of a given set of genes.

Keywords: psychologism, antipsychologism, neuroscience, naturalism, ontogenetic prerequisites of psychologism, Baldwin effect.

\section{References}

Aach, J. (1990). Psychologism reconsidered: A re-evaluation of the arguments of Frege and Husserl. Synthese, 85, 315-338.

Bazhanov, V. A. (2007). Istoriya logiki v Rossii i SSSR. Kontseptualmyi kontekst universitetskoi filosofii [The history of logic in Russia and the USSR. A conceptual context of the academic philosophy]. Moscow: Kanon+.

Bazhanov, V. A. (2008). Pervyi uchitel' A.R. Lurii: N.A. Vasiliev kak psikholog [The first teacher of A.R. Luria: N.A. Vasiliev as a psychologist]. Methodology and History of Psychology, 2, 69-78.

Bazhanov, V. A. (2009). N.A. Vasiliev i ego voobrazhaemaya logika. Voskreshenie odnoi zabytoi idei [N.A. Vasiliev and his imaginary logic. A revival of one forgotten idea]. Moscow: Kanon+.

Bazhanov, V. A. (2014). Raznovidnosti i protivostoyanie realizma i antirealizma v filosofii matematiki. Vozmozhna li tret'ya liniya? [Varieties and opposition of realism and antirealism in the philosophy of mathematics. Is there a third possible trend?]. Voprosy Filosofii, 5, 52-64.

Bazhanov, V. A. (2015). Modern neuroscience and the nature of the subject of cognition: a logico-epistemological study. Epistemology and Philosophy of Science, 3, 133-149. 
Belluz, J. (2015, August 27). Scientists replicated 100 recent psychology experiments. More than half of them failed. Retrieved from http://www.vox.com/2015/8/27/9216383/irreproducibilityresearch

Benthem van, J. (2008). Logic and reasoning: Do they matter? Studia Logica, 88, 67-84.

Boone, W., \& Piccinini, G. (2016). The cognitive neuroscience revolution. Synthese, 193, 1509-1534. doi:10/1007/s11229-015-0783-4

Bryushinkin, V. N. (1988). Logika, myshlenie, informatsiya [Logic, cognition, information]. Leningrad: Leningrad University Press.

Cantlon, J. F. (2012). Math, monkeys, and the developing brain. PNAS, 109, 10709-10716.

Chater, N., \& Christiansen, M. (2010). Language acquisition meets language evolution. Cognitive Science, 34, 1131-1157.

Chiao, J., Hariri, A., Harada, T., Mano, Y., Sadato, N., Parish, T., \& Iidaka, T. (2010). Theory and methods in cultural neuroscience. SCAN, 5, 356-361.

Collins, J. (2009). The limits of conceivability: Logical cognitivism and the language faculty. Synthese, $171,175-194$.

Copeland, J. (2013). Turing: Pioneer of the information age. Oxford: Oxford University Press.

De Vos, J. (2016). The death and the resurrection of [Psy]critique: The case of neuroeducation. Foundations of Science, 21(1), 129-145. doi:10.1007/s10699-014-9369-8

Dehaene, S. (2011). The number sense: How the mind creates mathematics. New York: Oxford University Press.

Fromm, E. (2007). Anatomiya chelovecheskoi destruktionosti [The anatomy of human destructiveness]. Moscow: AST.

Futrell, R., Mahowald, K., \& Gibson, E. (2015). Large-scale evidence of dependency length minimization in 37 languages. PNAS, 112(33), 10336-10341. doi:10/1073/pnas.1502134112

Gabbay, D., \& Woods, J. (2001). The new logic. Logic Journal of IGPL, 9(2), 141-174.

Grzegorczyk, A. (1998). Is antipsychologism still tenable? In Alfred Tarski and the Vienna Circle: Austro-Polish connections in logical empiricism (pp. 109-114). Dordrecht: Springer.

Haack, S. (1978). Philosophy of logics. Cambridge: Cambridge University Press.

Hall, E. (1966). The hidden dimension. New York: Doubleday.

Hanna, R. (2006). Rationality and logic. Cambridge, MA: MIT Press.

Heinz, Ch. (2005). Psychologism and the cognitive foundations of mathematics. Philosophia Scientiae, $9(2), 41-59$

Iacoboni, M. (2007). Neuroscience will change society. Retrieved from https:/www.edge.org/ q2007/q07_8.html\#iacoboni

Ivanov, V. V. (1978). Chet inechet. Asimmetriya mozga iznakorykh sistem [Odd and even. The asymmetry of brain and semiotic systems]. Moscow: Sovetskoe radio.

Jacquette, D. (1997). Psychologism the 3hilosophical Shibboleth. Philosophy and Rhetoric, 30, 312-331. Jacquette, D. (2003). Preface. In Philosophy, psychology, and psychologism (pp. IX-XI). New York/Boston/Dordrecht/London/Moscow: Kluwer Academic Publishers.

Kapustin, B. G. (2010). Kritika politicheskoi filosofii. Izbrannye esse [Critics of political philosophy. Selected essays]. Moscow: Territoriya budushchego.

Kasavin, I. T. (2011). Poznanie i yazyk [Cognition and language]. Epistemology and Philosophy of Science, 4, 5-15.

Kinzler, K. D., \& Spelke, E. S. (2007). Core systems in human cognition. In C. von Hofsen \& K. Rosander (Eds.), Progress in brain research (Vol. 164, pp. 257-264). Oxford: Elsevier. 
Kusch, M. (1995). Psychologism. A case study in the sociology of philosophical knowledge. London/New York: Routledge.

Kusch, M. (2015). Psychologism. In Stanford encyclopedia of philosophy. Retrieved from http://plato.stanford.edu/entries/psychologism

Kuznetsova, N. I. (1986). Istoriya nauki kak gumanitarnaya distsiplina [History of science as a humanitarian science]. In Problemy gumanitarnogo poznaniya [Issues of humanitarian cognition] (pp. 141-168). Novosibirsk: Nauka.

Lehan-Streisel, V. (2012). Why philosophy needs logical psychologism. Dialogue, 51(4), 575-586.

Levinson, S. C. (2003). Space in language and cognition. Cambridge University Press.

Lubkin, A. S. (1807). Nachertanie logiki [Pattern of logic]. Saint Petersburg.

Macnamara, J., \& Reyes, G. E. (Eds.). (1994). The logical foundation of cognition. New York: Oxford University Press.

Maslov, S. Yu. (1986). Teoriya deduktiomykh sistem i ee primeneniya [Theory of deductive systems and its application]. Mosow: Radio i svyaz'.

Neumann von, J. (2000). The computer and the brain (2nd ed.). New Haven, CT: Yale University Press.

Pearson, K. A., \& Protive, J. (2016). Naturalism in the continental tradition. In K. J. Clark (Ed.), Blackwell companion to naturalism (pp. 34-48). Cambridge, MA: Wiley.

Pechhaus, V. (1999). 19th century logic between philosophy and mathematics. The Bulletin of Symbolic Logic, 4, 433-450.

Pelletier, F, \& Elio, R. (2005). The case for psychologism in default and inheritance reasoning. Synthese, 146, 7-35.

Pelletier, F., Elio, R., \& Hanson, P. (2008). Is logic all in our heads? From naturalism to psychologism. Studia Logica, 85, 1-65.

Pitt, D. (2009). Intentional psychologism. Philosophical Studies, 146, 117-138. doi:10.1007/s11098008-9247-8

Popova, V. S. (2015). Psychologism as the logical and methodological issue: Historical origin in Russian philosophy of the beginning of the XXth century and contemporary meaning. Psychology and Psychotechnics, 6, 570-577. doi:10.7256/2070-8955.2015.6.15508 (in Russian)

Prigogine, I., \& Stengers, I. (1994). Vremya, khaos, kvant [Time, chaos, quantum]. Moscow: Progress.

Rizzolatti, G., \& Craighero, L. (2009). Language and mirror neurons. In Oxford handbook of psycholinguistics (pp. 771-785). Oxford: Oxford University Press.

Shalak, V. I. (2014). Protologic and its structure. Logical Investigations, 20, 198-212. (in Russian)

Sorina G. V. (1993). Logiko-kul'turnaya dominanta. Ocherki teorii i istorii psikhologizma $i$ antipsikhologizma v kul'ture [Logico-cultural dominant. Essays on the theory and history of psychologism and anti-psychologism in culture]. Moscow: Prometei.

Sorina, G. V. (2012). Proekt "psikhologizm-antipsikhologizm" v metateoreticheskom kontekste. [Project "psychologism-anti-psychologism in the meta-theoretical context]. Ratsio.ru, 8, 20-45.

Sorina, G. V. (2016). Dialogue of the methodological concepts. The Siberian Journal of Philosophy, 14(1), 280-297. (in Russian)

Stenning K., \& Lambalgen von, M. (2008). Introduction: Logic and psychology. In Human reasoning and cognitive science (pp. II-XI). Cambridge, MT: MIT Press.

Thagard, P. (1993). Computational philosophy of science. Cambridge, MA/London: The MIT Press.

Trostnikov, V. N. (1975). Konstniktirmye protsessy v matematike [Constructive processes in mathematics]. Moscow: Nauka. 
Urbanski, M. (2011). Logic and cognition: Two faces of psychologism. Logic and Logical Philosophy, 20, $175-185$.

Vachkov, I. V., \& Vachkova, S. N. (2016). Reproducibility of psychological experiments as a problem of post-nonclassical science. Kulturno-istoricheskaya psikhologiya [Cultural-Historical Psychology], 12(1), 97-101. doi:10.17759/chp.2016120110 (in Russian)

Vasiliev, N. A. (1912). Voobrazhaemaya (nearistoteleva) logika [Imaginary (non-Aristotelian) logic]. Zhumal Ministerstva Narodnogo Prosveshcheniya. Novaya Seriya, August, 207-246.

Wheatley, M. J. (1992). Leadership and the new science. Learning about organization from and orderly universe. San Francisco: Berret-Koehler Publ.

Zhdan, A. N. (2012). V.N. Ivanovskii kak myslitel' [V.N. Ivanovsky as a thinker]. In V. A. Bazhanov (Ed.), Logiko-gnoseologicheskoe napravlenie v otechestvennoi filosofii (pervaya polovina XX veka): M.I. Karinskii, V.N. Ivanovskii, N.A. Vasiliev [Logico-epistemological trend in the Russian philosophy (first half of the XX century): M.I. Karinsky, V.N. Ivanovsky, N.A. Vasiliev] (pp. 127-182). Moscow: ROSSPEN.

Valentin A. Bazhanov - head, Department of philosophy, Ulyanovsk State University, D.Sc., professor.

Research area: history and philosophy of science, epistemology, cultural neuroscience, history of Russian philosophy and logic.

E-mail: vbazhanov@yandex.ru 